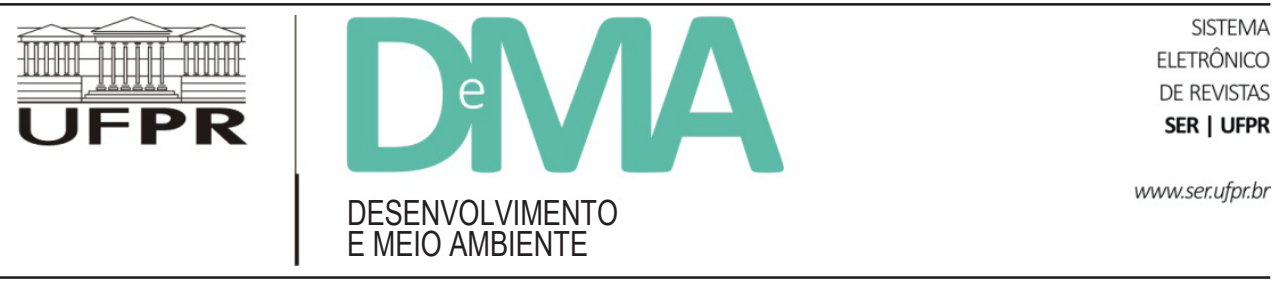

\title{
Conflitos entre o Comperj e a gestão de áreas protegidas: o Mosaico Central Fluminense como possibilidade de enfrentamento a impactos socioambientais de grandes empreendimentos industriais
}

\section{Conflicts between the Comperj and the Management of Protected Areas: the Central Fluminense Mosaic as a Possibility of Confronting Socio-Environmental Impacts from Large Industrial Enterprises}

\author{
Breno Herrera da Silva COELHO ${ }^{1,2^{*}}$, Carlos Frederico LOUREIRO ${ }^{1}$, Marta Azevedo IRVING ${ }^{1}$, David Gomes \\ SOARES $^{3}$ \\ ${ }^{1}$ Programa de Psicossociologia de Comunidades e Ecologia Social (EICOS), Universidade Federal do Rio de Janeiro (UFRJ), Rio de Janeiro, \\ RJ, Brasil. \\ ${ }^{2}$ Instituto Chico Mendes (ICMBio), Brasil. \\ ${ }^{3}$ Instituto de Ciências Sociais, Universidade do Estado do Rio de Janeiro (UERJ), Rio de Janeiro, RJ, Brasil. \\ *E-mail de contato: breno.herrera@gmail.com
}

Artigo recebido em 12 de julho de 2015, versão final aceita em 24 de novembro de 2015.

RESUMO: A implantação do Complexo Petroquímico do Rio Janeiro - Comperj, na cidade de Itaboraí-RJ, tende a gerar impactos socioambientais sobre as unidades de conservação circundantes, reunidas no âmbito do Mosaico da Mata Atlântica Central Fluminense (MCF). Durante o processo de licenciamento ambiental desse empreendimento foram constatadas contradições, que ensejaram tensões com as áreas protegidas, movimentos sociais e o Ministério Público Federal. Interpretando este caso à luz da ecologia política e da justiça ambiental, o presente trabalho discorre sobre a ação institucional dos conselhos de mosaicos e de unidades de conservação na gestão e no enfrentamento dos impactos socioambientais associados à instalação de grandes empreendimentos industriais, destacando em particular a atuação do conselho do MCF e sua capacidade de mediação com os setores empresarial e governamental.

Palavras-chave: mosaicos de áreas protegidas; licenciamento ambiental; mediação de interesses; conflitos.

ABSTRACT: The implementation of the Petrochemical Complex of Rio de Janeiro - COMPERJ in the city of Itaboraí-RJ, tends to generate social and environmental impacts on the surrounding protected areas, within the Atlantic Forest Central Fluminense Mosaic (MCF). During the licensing process of this enterprise, contradictions were found, which rose tensions among protected areas, social movements and the Federal Prosecution Service. 
Interpreting this case in light of concepts used in the field of political ecology and environmental justice, this paper discusses the institutional action of the councils of mosaics and protected areas in managing as well as addressing social and environmental impacts associated with the installation of large industrial enterprises, highlighting in particular the role of the council of the MCF and its mediation capacity with the government and corporate sectors.

Keywords: protected areas mosaics; environmental licensing; interests mediation; conflicts.

\section{Introdução}

O presente trabalho analisa o caso do licenciamento ambiental do Complexo Petroquímico do Rio de Janeiro - Comperj - em suas interfaces com as unidades de conservação da natureza componentes do Mosaico da Mata Atlântica Central Fluminense (MCF). Contradições e conflitos havidos no processo de licenciamento são descritos, bem como a atuação institucional do conselho do Mosaico, por vezes em conjunto com o Ministério Público Federal, no sentido de questioná-los, objetivando reduzir os impactos socioambientais negativos sobre a biodiversidade regional, os povos tradicionais e demais grupos vulnerabilizados socialmente e ambientalmente.

Neste sentido, são cotejados ao caso alguns conceitos seminais identificados no campo da ecologia política e da justiça ambiental, tal como proposto por Loureiro (2012): a falha metabólica entre sociedade e natureza (Foster, 2005), a interpretação das principais correntes do ecologismo (Martínez-Alier, 2011), a chantagem ambiental e as zonas de sacrifício (Bullard, 1994). A partir deste arcabouço teórico, foi adotada uma abordagem materialista histórico-dialética, pressupondo-a como apropriada para evidenciar os conflitos socioambientais estruturais da sociedade e para esclarecer as tensões geradas entre duas lógicas distintas nos processos de licenciamento ambiental: a lógica de reprodução do capital, dependente dos mecanismos regulatórios do Estado, e a lógica de reprodução da natureza (Acselrad, 2004; Foster, 2005). Tal abordagem se justifica, ainda, em função de sua afinidade com a corrente denominada de ecologismo dos pobres ${ }^{1}$ por Martínez-Alier (2011), mais conhecida como movimento de justiça ambiental na América Latina e do Norte (Acselrad et al., 2009; Loureiro \& Layrargues, 2013).

As ferramentas metodológicas empregadas foram análise bibliográfica e revisão documental - por meio de consulta aos estudos ambientais, pareceres, relatórios e documentos oficiais envolvidos no processo de licenciamento; bem como observação participante, decorrente da proximidade de autores deste artigo junto aos processos sociais conflituosos estudados, que atuaram no licenciamento do Comperj a partir de suas inserções junto às unidades de conservação componentes do Mosaico.

Por intermédio do caso selecionado, investigou-se a ação institucional dos mosaicos de unidades de conservação no enfrentamento de tensões e conflitos socioambientais decorrentes do licenciamento de grandes empreendimentos industriais, tendo por referência empírica os conselhos de unidades de conservação (UCs) e do Mosaico Central Fluminense. Trata-se, portanto, de material relevante para a compreensão das contradições inerentes à reorganização territorial estabelecida no processo de desenvolvimento e para o campo teórico da ecologia política e da justiça ambiental, à medida que vincula a temática da conservação da biodiversidade com aspectos sociopolíticos relacionados aos interesses econômicos que sustentam projetos industriais como o Complexo Petroquímico do Rio de Janeiro.

\footnotetext{
${ }^{1}$ Esta corrente do ambientalismo, de acordo com Martínez-Alier (2011), surgiu por meio de conflitos socioambientais causados pelo crescimento econômico e pela desigualdade social, como no movimento pelas reservas extrativistas, liderado por Chico Mendes na Amazônia brasileira, e o movimento Chipko, na Índia. No ecologismo dos pobres, parte-se do pressuposto de que a degradação ambiental resulta em danos sofridos de forma assimétrica pela população, restando aos grupos mais pobres os principais efeitos negativos do desequilíbrio ecológico. Nesta corrente, os esforços ligados à conservação necessariamente devem se vincular ao enfrentamento da desigualdade social.
} 


\section{Mosaicos de áreas protegidas como novos atores políticos regionais}

Conforme Irving (2010), nas últimas três décadas as políticas de conservação da biodiversidade vêm sendo marcadas por esforços em conciliar a preservação stricto sensu da biota com ações de inclusão social. Em 2003, por exemplo, a IUCN (International Union for Conservation of Nature), instituição reconhecida por seu viés tradicionalmente preservacionista - alinhado à corrente do culto ao silvestre, conforme conceituada por Martínez-Alier ${ }^{2}$ - organizou o V Congresso Mundial de Parques sob o lema "Benefits Beyond Boundaries", abrindo o escopo das discussões de modo a considerar como as unidades de conservação contribuem para o desenvolvimento socioeconômico regional, para além de seus limites geográficos e de parâmetros estritamente biológicos.

Este entendimento acerca da potencial integração das unidades de conservação com seu entorno correspondeu a inovações também refletidas na política brasileira de conservação da biodiversidade. Neste sentido, entre outros aspectos, o Sistema Nacional de Unidades de Conservação - SNUC - (Brasil, 2000) formalizou o conceito de mosaicos de unidades de conservação, em seu artigo 26, onde se lê que:

Quando existir um conjunto de unidades de conservação de categorias diferentes ou não, próximas, justapostas ou sobrepostas, e outras áreas protegidas públicas ou privadas, constituindo um mosaico, a gestão do conjunto deverá ser feita de forma integrada e participativa, considerando-se os seus distintos objetivos de conservação, de forma a compatibilizar a presença da biodiversidade, a valorização da sociodiversidade e o desenvolvimento sustentável no contexto regional.

Resumidamente, os mosaicos representam um modelo de gestão de unidades de conservação que privilegia a integração de diferentes UCs entre si e com seu entorno, possibilitando uma extensão da gestão do nível local ao regional e uma lógica gerencial territorial, que pressupõe a articulação das políticas de conservação da natureza a outras políticas públicas que definem diferentes (e desiguais) formas de usos da natureza (Loureiro et al., 2014). Os mosaicos possibilitam uma gestão comunicativa e integrada entre as diversas unidades de conservação que o compõem, propiciando uma visão de conjunto para a gestão ambiental, o que representa um distanciamento da noção tradicional de isolamento social e político representada pela imagem de "ilhas de conservação" - frequentemente associada às unidades de conservação.

O Mosaico Central Fluminense ${ }^{3}$, objeto de análise do presente trabalho, abrange $35 \mathrm{UCs}$, dentre federais, estaduais, municipais e privadas, totalizando uma área de cerca de 220.000 ha nas cercanias da região serrana central do Estado do Rio de Janeiro (Costa et al., 2010; Melo, 2012). Protege valiosa diversidade ecossistêmica, incluindo campos de altitude, mata atlântica montana e de baixada, manguezais e ambiente marinho.

Operacionalmente, a instância gestora do mosaico é seu conselho ${ }^{4}$ consultivo, composto por representantes das UCs componentes (o chefe da cada UC, mais um representante da sociedade civil de cada unidade), dos comitês de bacias hidrográficas da região e de instituições de pesquisa com atuação no território. O conselho do Mosaico Central Fluminense está em atividade re-

\footnotetext{
${ }^{2}$ Culto à vida silvestre: caracteriza-se pela ênfase na manutenção de áreas protegidas e pela admiração da natureza por seus valores intrínsecos. Tem na biologia da conservação sua principal sustentação científica e nas políticas conservacionistas (como a Convenção sobre a Diversidade Biológica, em âmbito internacional, e os sistemas de áreas protegidas, em âmbito nacional) seu principal desdobramento aplicado. O culto ao silvestre não se contrapõe ao sistema econômico vigente (Martínez-Alier, 2011).

${ }^{3}$ O Ministério do Meio Ambiente reconheceu até o momento quatorze mosaicos (ICMBio, 2014), dentre os quais o Mosaico da Mata Atlântica Central Fluminense.

${ }^{4}$ O SNUC determina que UCs (Lei Federal 9.985/2000; arts. 15, § 5 ; 16, § 5 ; $18, \S 2^{\circ} ; 20, \S 4^{\circ}$ e 29) e mosaicos (Decreto 4340/2002; art. $9^{\circ}$ ) disponham de conselhos gestores: colegiados que participam da gestão da unidade, consultiva ou deliberativamente, dependendo da categoria da UC, compostos por representantes dos órgãos públicos e da sociedade civil, como ONGs, OSCIPs, associações de moradores locais, colônias de pesca, etc.
} 


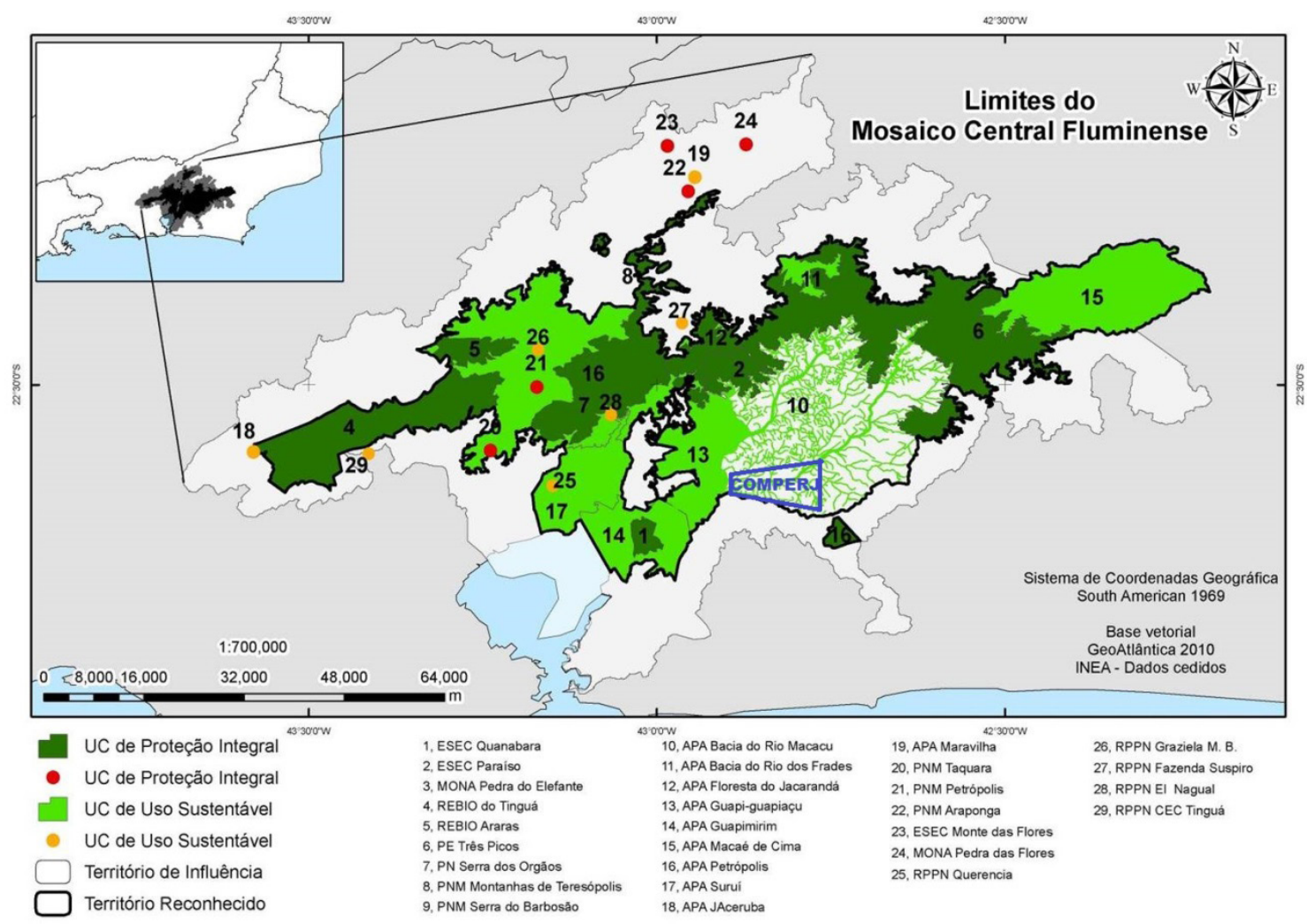

FIGURA 1 - Área do Mosaico Central Fluminense, destacando a localização do Comperj5.

gular e ininterrupta desde seu reconhecimento oficial, em 2006, e vem sendo considerado como modelo para outros mosaicos brasileiros, dados os avanços obtidos na gestão integrada das unidades de conservação e na articulação com diferentes grupos sociais presentes em seu território (Delelis et al., 2010; Loureiro et al., 2014).

No âmbito da presente pesquisa, os conselhos gestores são entendidos como sujeitos coletivos, a partir da perspectiva da teoria do ator rede (Latour, 2005). Segundo esta perspectiva, o ator é definido a partir do papel que desempenha - quão ativo e repercussivo é e quanto efeito produz em sua rede (entendida como a interligação de conexões - nós - onde os atores estão envolvidos); neste contexto, não apenas pessoas, mas também instituições e agrupamentos coletivos podem ser considerados como atores ou actantes (Law, 1992; Freire, 2006).

\section{O Comperj no contexto do PAC e os impactos sobre as Unidades de Conservação}

Em 2007, na reeleição do presidente Lula, foi lançado o Programa de Aceleração do Crescimento -

\footnotetext{
${ }^{5}$ Ao lado das UCs listadas na figura 1 - representadas por seus chefes (UCs federais e estaduais) ou responsáveis indicados pelas secretarias de meio ambiente (UCs municipais) -, compõem o conselho do Mosaico Central Fluminense as seguintes entidades: instituições de pesquisa: UFRJ, UERJ, Fiocruz e Embrapa; associações do terceiro setor: IBIO, Instituto Ipanema (Rio de Janeiro); Innatus, OIA (Petrópolis); Regua (Cachoeiras de Macacu); Instituto Tecnoarte (Guapimirim) e Tereviva (Teresópolis); e entidades da sociedade civil eleitas pelos comitês de bacia hidrográfica da Baía de Guanabara; Guandu; Paraíba do Sul e Piabanha, Preto e Paquequer.
} 
PAC - pelo governo federal. O programa envolve um conjunto de projetos prioritariamente infraestruturais e energéticos voltados a fornecer bases para viabilizar uma aceleração da atividade econômica brasileira.

Leher (2007) vincula o PAC a outros programas similares que estão ocorrendo na América Latina, agrupados na Iniciativa para Integração da Infraestrutura Regional Sul-Americana - IIRSA, como parte de uma tendência econômica global de reprimarização da economia capitalista periférica. Na economia contemporânea globalizada, a reprodução internacional do capital exige que países portadores de abundantes recursos naturais (bens primários) dirijam seus investimentos públicos e esforços políticos na ampliação da oferta de commodities - usualmente produtos de baixo valor agregado (o que deteriora a balança comercial do país produtor) - e energointensivos (o que impõe intrínsecos danos ecológicos). Na geopolítica e na geoeconomia mundial, a tendência de países periféricos ao capitalismo, como o Brasil (Brandão, 2010), é assumir um caráter dependente - pela subordinação econômica aos mercados afluentes - e desigual - dada a deterioração dos valores de troca entre os bens primários exportados e os bens derivados importados.

Após um período de grande endividamento externo e baixo crescimento, durante os anos 1980 e 1990, a economia brasileira voltou a crescer nos anos 2000. Tal crescimento ancorou-se principalmente no citado processo de reprimarização da economia, com expansão do agronegócio e da exploração mineral (metais e petróleo). Este momento da economia nacional é caracterizado por alguns autores como neodesenvolvimentismo, inserido na dinâmica do capitalismo dependente (Paula, 2010), o que determina a reorganização territorial com base na precificação da natureza e na criação de territórios desigualmente ordenados, com impactos diretos no equilíbrio ecossistêmico e na possibilidade de reprodução do modo de vida dos povos tradicionais (Pacheco
\& Faustino, 2013; Leroy \& Meireles, 2013). O PAC expressa, desta forma, a marca político-econômica do neodesenvolvimentismo brasileiro.

A maior obra do PAC no Estado do Rio de Janeiro é o Complexo Petroquímico do Rio de Janeiro - Comperj. De fato, a Petrobras (corporação majoritária no consórcio empresarial criado para viabilizar o empreendimento) apresenta a obra em seu material de divulgação pública como o maior investimento individual de sua história: o volume inicial do empreendimento foi anunciado em cerca de oito bilhões de dólares ${ }^{6}$. Trata-se de um complexo de atividades petroquímicas voltadas à produção de resinas termoplásticas e combustíveis, a partir do refino do petróleo pesado produzido na bacia de Campos (Concremat, 2007).

Dentre todas as atividades envolvidas na cadeia produtiva do petróleo brasileiro, o refino é a mais defasada do ponto de vista do incremento tecnológico e da prevenção de riscos. Um dos resultados desta defasagem assumiu dimensão catastrófica quando do acidente da Refinaria de Duque de Caxias, em 2000, o mais grave já ocorrido na Baía de Guanabara ${ }^{7}$, em decorrência do desgaste de oleodutos com manutenção precária (Coelho, 2002). Contrariamente, outras atividades, como a exploração e a produção em águas profundas, fazem da Petrobras referência internacional no ramo. Neste aspecto, ou seja, sob a ótica da política energética convencional, o investimento no refino vem equilibrar a cadeia produtiva petrolífera/petroquímica brasileira, além de contribuir com a balança comercial, uma vez que o Comperj utilizará matéria-prima doméstica, em oposição ao parque de refino já instalado no país, adaptado ao emprego de petróleo leve internacional.

Atrasos no cronograma das obras, aliados a dificuldades financeiras, levaram a Petrobras a adiar a perspectiva de início das operações do Comperj para agosto de 2016 - a estimativa inicial era 2012. Houve também uma reorientação das atividades da refinaria: em um

\footnotetext{
${ }^{6}$ Tal valor inicialmente anunciado quando o empreendimento foi lançado sofreu significativos acréscimos posteriores, em decorrência de adições de contratos licitatórios e desvios de verbas revelados pela operação Lava-Jato da Polícia Federal. Em 2014, a Petrobras atualizou o valor do investimento para US\$13,5 bilhões (Alencar \& Galdo, 2015).

${ }^{7}$ Conforme Soares (2012), outro acidente de grandes proporções na Baía de Guanabara ocorreu em 1975, com o naufrágio do navio Tarik, que liberou cerca de 6.000 galões de óleo em toda Baía de Guanabara. Todavia, enfatiza-se aqui o derramamento de 2000 por ter sido de tão grande proporção e ainda em um momento cujas sensibilidades para a questão ambiental já estavam afloradas.
} 
primeiro momento, o Complexo se destinará à produção de combustíveis, ficando a produção de plásticos adiada (Alencar \& Galdo, 2015).

Localizado no município de Itaboraí, com área de cerca de 4.500 ha, o Comperj se encontra dentro dos limites do Mosaico de Unidades de Conservação da Mata Atlântica Central Fluminense. Está inserido na Área de Proteção Ambiental (APA) estadual do Macacu, limítrofe à APA Guapi-guapiaçu (sob administração do município de Guapimirim), a menos de $10 \mathrm{~km}$ à montante da APA Guapimirim e da Estação Ecológica (ESEC) Guanabara e a menos de $20 \mathrm{~km}$ do Parque Nacional da Serra dos Órgãos.

A proximidade com importantes unidades de conservação vem gerando intensa preocupação acerca da manutenção da qualidade ambiental da região. A área circundante do Comperj apresenta a maior concentração de UC no Estado, equiparada à região da costa verde, no sul fluminense. Trata-se da última região do entorno da Baía de Guanabara ainda com considerável qualidade de águas, uso do solo predominantemente agropecuário e baixa atividade industrial poluente (Amador, 2000).

A dimensão dos riscos socioambientais que a instalação do Comperj representa é fortalecida na memória local de acidentes envolvendo petróleo e derivados que atingiram os manguezais do recôncavo da baía nos últimos anos, causando impactos sobre a biota. Dentre estes, o já citado acidente da Refinaria Duque de Caxias, em janeiro de 2000, e o acidente da Ferrovia Centro Atlântica, em abril de 2005, quando cerca de 60.000 litros de óleo diesel atingiram o rio Caceribu ${ }^{8}$. Estes casos evidenciaram, sobretudo para alguns atores sociais da região (comunidades de pescadores, ONGs ambientalistas, gestores das UCs locais), que o risco relacionado à atividade petrolífera não decresceu apenas com maiores investimento em segurança e prevenção . Essa não parece uma questão exclusiva da indústria de petróleo, pois, conforme Giddens (1990) e também Beck (2010) afirmam, uma sociedade de risco está diretamente associada à construção continuada de incertezas e riscos adicionais pelo uso da racionalidade científica associada à racionalidade econômica e à burocracia estatal. Este tipo de racionalidade moderna, embora originalmente associada a uma noção de aumento de controle (ambiental, social, psíquico, educacional) pelo acúmulo de conhecimento científico, objetivamente desde o último quartel do século XX é produtora permanente de novos riscos e de novas incertezas. O que permite colocar em dúvida sua capacidade de controle diante da ampliação de casos de danos e conflitos socioambientais (Almeida, 2010; Zhouri \& Valencio, 2014).

Além do risco de acidentes, a própria implantação e a operação regular do empreendimento tendem a gerar impactos socioambientais de proporções consideráveis, destacando os efeitos sobre os direitos dos povos tradicionais (pescadores artesanais e camponeses), a poluição atmosférica e a alteração do fluxo hídrico, melhor descrita a seguir (Ibama-ICMBio, 2008).

A região do Comperj está sujeita a problemas de oferta adicional de água, que devem ser considerados no caso estudado, dado o significativo volume necessário para o empreendimento. O Estudo de Impacto Ambiental - EIA - do empreendimento (Concremat, 2007) indica a escassez de água da região: "a região de interesse tem o abastecimento de água deficitário”. O Plano Diretor de Recursos Hídricos da Baía de Guanabara - PDRH-BG, aprovado pelo Governo do Estado do Rio de Janeiro um ano antes do início do licenciamento do Comperj (Feema-Serla, 2005), que serve como principal elemento de planejamento para o uso de água para a bacia

\footnotetext{
${ }^{8}$ Este rio pertence à bacia hidrográfica da Baía de Guanabara, desaguando na baía na fronteira dos municípios de Guapimirim e Itaboraí e no limite entre a APA Guapimirim e a ESEC Guanabara.

${ }^{9}$ Após o derramamento de óleo de 2000, a Petrobras criou o programa PEGASO - Programa de Excelência em Gestão Ambiental e Segurança Operacional, que foi considerado o maior projeto em nível mundial já destinado a um programa ambiental do setor de petróleo. Segundo a classificação de Martínez-Alier (2011), este projeto enquadra-se na corrente do evangelho da ecoeficiência. Esta corrente se pauta nos conceitos de desenvolvimento sustentável, modernização ecológica e na utilização racional dos recursos naturais. Preocupa-se com os impactos da produção de bens e com o manejo sustentável dos recursos naturais, e não tanto pela perda dos atrativos da natureza ou dos seus valores intrínsecos. Considera que os problemas ambientais devem ser tratados na esfera da ciência instrumental e da modernização tecnológica. Assim, a ecologia se converte em uma ciência gerencial para limpar ou remediar a degradação causada pela industrialização (Visvanathan, 1997 apud Martínez-Alier, 2011).
} 
hidrográfica da baía, aponta que a região onde está se instalando o Comperj é inadequada para a instalação de atividades industriais:

Os resultados indicam que é aconselhável que se proceda à preservação destas águas, impedindo-se a localização de indústrias poluidoras na sua área de influência (Feema-Serla, 2005).

O referido Plano orienta ainda a priorização do uso das águas da região para o abastecimento humano:

Garantir a qualidade da água dos mananciais da área leste da bacia, que deverão ser preservados como fonte de abastecimento humano (Feema-Serla. 2005).

Além das necessidades humanas diretas, há a vazão ecológica que deve ser mantida para a conservação dos ecossistemas à jusante, notadamente os manguezais protegidos pela APA Guapimirim e ESEC Guanabara ${ }^{10}$. Neste sentido, deve-se considerar a recarga das águas subterrâneas, que será afetada sensivelmente, já que o solo da região é composto majoritariamente por planícies de inundação. A simples pavimentação necessária para implantação da planta industrial alterará a recarga das águas subterrâneas, conforme o próprio EIA do empreendimento indica:

A área do empreendimento se projeta, em parte, na planície de inundação das bacias, local onde hidrologicamente se verifica a laminação de cheias e se processam os mecanismos de troca de água dos rios, de modo que nos períodos de maior vazão a água inunda estas planícies, satura os solos, recarga os lençóis freáticos de modo a acumular água para liberá-la nos períodos de estiagem, contribuindo para a reposição das vazões destas áreas (Concremat, 2007).
Não se pode negligenciar também que os impactos no regime hidrológico local decorrentes da implantação do Comperj tenderão a se agravar pelo aumento das taxas de urbanização e crescimento industrial esperados com a chegada de um empreendimento deste porte na região. Em vários momentos, o EIA indica a previsão de instalação de outras empresas petroquímicas nas cercanias, motivadas pela proximidade com a fonte de matéria-prima a ser gerada para a indústria de plásticos. Segundo projeções da Fundação Getúlio Vargas, empresa contratada para realizar parte dos estudos de impacto ambiental do Comperj, é prevista pelos próximos anos a instalação de pelo menos 720 empresas nas proximidades do empreendimento e ao longo do arco metropolitano (Soares, 2012). Consequência inevitável do adensamento industrial é o respectivo adensamento urbano. Portanto, não só o Comperj isoladamente, mas as demais atividades industriais e a explosão de ocupação urbana esperadas alterarão significativamente a cobertura do solo, com aterros e pavimentações, reduzindo a capacidade de recarga da planície de inundação. Novamente, o Plano Diretor de Recursos Hídricos da Baía de Guanabara aponta considerações importantes, quando propõe que:

É preciso impedir que áreas inundáveis ainda não ocupadas venham a ser urbanizadas, evitando assim futuros problemas. Recomenda-se delimitar estas áreas e criar legislação nos respectivos municípios tornando-as não urbanizáveis (Feema-Serla, 2005).

Analisando à luz da ecologia política as contradições havidas entre as condições ecológicas da região e as imposições da atividade industrial, é possível inferir que o caso reproduz um padrão internacional do desenvolvimento, cujo caráter expropriador de seu modo de produção leva à falha metabólica entre sociedade e natureza. Segundo Foster (2005), tal falha se dá quando a relação metabólica - estabelecida pelo trabalho - entre sociedade e natureza é alienada por meio da separação

\footnotetext{
${ }^{10}$ Ecossistemas de manguezal dependem para seu funcionamento do equilíbrio entre a água salgada marinha e a água dos rios que neles desembocam. Eventuais reduções no aporte de água doce podem gerar avanço da cunha salina marinha. O aumento da salinidade decorrente, dependendo de sua intensidade, pode inviabilizar a permanência dos bosques de mangue. Para assegurar a sobrevivência destes ecossistemas, seja no equilíbrio de salinidade, seja na própria oferta de água necessária para manutenção de seus processos ecológicos e geomorfológicos, há de se considerar um mínimo de vazão hidrológica que abasteça os bosques de mangue. Essa vazão mínima é definida como vazão ecológica.
} 
entre os seres humanos e as condições naturais que formam a base de sua existência enquanto ser social (Lukács, 2013). Ilustrando tal conceito no caso estudado, Amador (2000) e Langenbach et al. (2008) descrevem como o processo de desenvolvimento urbano-industrial do entorno da baía de Guanabara coincide com a depreciação da qualidade ambiental deste ecossistema - à medida que as indústrias foram se instalando, as populações nativas foram se distanciando de uma relação direta com os recursos naturais, que passou a ser mediada por relações capitalistas de afastamento dos trabalhadores (como o caso dos pescadores artesanais e camponeses) do seu meio de produção (respectivamente, ambiente marinho, sendo progressivamente degradado pela poluição urbano-industrial, e campos agricultáveis seminaturais, continuamente convertidos em paisagens urbano-industriais). Neste propósito, citamos Giuliani (1999):

A indústria como sistema produtivo é conatural às relações sociais capitalistas, não somente porque nasce dentro destas e porque representa a definitiva afirmação do capitalismo sobre qualquer outro modo de produzir anterior. Indústria e capitalismo estão em simbiose, porque qualquer sistema de produção é, como dizia Marx, ao mesmo tempo um sistema de reprodução (Giuliani, 1999).

Nesse escopo teórico, é também possível afirmar que a área escolhida para a implantação do Comperj, em decorrência dos impactos ambientais diretamente associados, pode ser classificada como uma zona de sacrifício. Bullard (1994), ao introduzir tal conceito, apresenta uma série de estudos geográficos, demográficos e estatísticos que apontam uma grande assimetria quanto à distribuição dos efeitos negativos da degradação ambiental na sociedade estadunidense. Instalações industriais poluentes, como refinarias, indústrias químicas e aterros sanitários concentram-se naquele país principalmente nas cercanias de bairros majoritariamente ocupados por populações afrodescendentes. Há, desta forma, um forte componente racial e classista na distribuição da poluição ambiental, restando às populações desfavorecidas (negros, em particular; pobres, em geral) a habitação próxima às chamadas zonas de sacrifício, que se caracterizam como áreas com suas qualidades ambientais "sacrificadas" em nome do desenvolvimento industrial. Este trabalho seminal de Bullard apontou que o "sacrifício" da sociedade para transformar a natureza, estabelecer formas de organização social e colher os benefícios do crescimento econômico é estruturalmente desigual e, portanto, esforços pela melhoria da qualidade ambiental que não considerem a redução das desigualdades sociais serão sempre reprodutores desta mesma desigualdade, mesmo que com padrões gerenciais e tecnológicos que minimizem os danos ambientais.

O Estado, ao definir pela não instalação do Comperj em áreas dominadas pelo agronegócio (indústria sucroalcooleira em Campos, conforme exposto a seguir), determinou que este se localizasse em região com populações mais desfavorecidas economicamente (pequenos agricultores de Itaboraí e pescadores artesanais do fundo da Baía de Guanabara). Testemunha-se aqui a alocação e distribuição desigual dos efeitos negativos da industrialização.

\section{Processo de licenciamento ambiental e atuação dos conselhos gestores}

No início da primeira década deste século, houve uma forte campanha no Estado do Rio de Janeiro para garantir que uma refinaria de grandes proporções anunciada pela Petrobras fosse instalada no Estado. O governo estadual exibia em seus expedientes oficiais, bem como em suas viaturas, um logotipo que dizia textualmente: "A refinaria é nossa"11.

Uma vez definido que o Rio de Janeiro sediaria a refinaria, iniciaram-se discussões sobre sua localização, sendo as duas cidades cotadas Campos e Itaguaí. Quando se deu o anúncio definitivo do governo federal, nenhuma das municipalidades postulantes anteriores

\footnotetext{
${ }^{11}$ Era o governo de Rosinha Garotinho, opositor ao governo federal, que, da mesma forma que a gestão anterior de Anthony Garotinho, mantinha sua principal base eleitoral em Campos, no norte fluminense.
} 
foi contemplada, mas sim o município de Itaboraí, uma escolha problemática do ponto de vista ambiental, conforme os argumentos acima expostos. Apesar de a legislação ambiental brasileira ser explícita quanto à necessidade de apresentação de alternativas locacionais para empreendimentos poluidores (Conama, 1986), esta questão foi praticamente desconsiderada no licenciamento ambiental do Comperj. Das cerca de 10.000 páginas do EIA, menos de 10 são dedicadas à análise locacional, sendo os argumentos apresentados para a exclusão da alternativa Campos considerados por alguns peritos e analistas ambientais do IBAMA de difícil aceitação. Sob quaisquer aspectos ambientais, seria a alternativa mais viável, destacando que haveria apenas uma UC dentro de um raio de $20 \mathrm{~km}$ do empreendimento, número comparativamente reduzido ao que se encontra em Itaboraí, como será visto adiante. Um dos argumentos apresentados para a exclusão de Campos, por exemplo, refere-se ao possível comprometimento das plantações de cana-de-açúcar da região, demonstrando de forma declarada que a importância de plantações de cana foi interpretada como significativamente superior, por sua valoração econômica e importância política, que a de áreas de vegetação nativa, protegidas por UCs.

O EIA não aponta de onde será a adução de água na localidade Itaboraí, o que se constitui como um dos aspectos mais relevantes a fundamentar decisões sobre a viabilidade ambiental da locação. Em Campos, a questão do abastecimento hídrico se resolveria utilizando as águas próximas à foz do rio Paraíba do Sul, o mais caudaloso do Estado, o que evitaria problemas em relação ao volume de água necessário e ao ponto de captação, que seria à jusante (após) quaisquer usos mais nobres, como abastecimento humano e conservação da biodiversidade.

Não considera também o EIA, assim como não atentou o órgão ambiental estadual em sua licença, os efeitos sinergéticos dos impactos gerados pelo Comperj somados a uma série de outras atividades poluidoras em processo de licenciamento ou recentemente licenciadas na região, como os terminais de gás natural liquefeito $\mathrm{e}$ gás liquefeito de petróleo na Baía de Guanabara, o arco rodoviário metropolitano, o gasoduto Reduc-Cabiúnas e a ampliação da Reduc. Novamente há flagrante dissonância com a legislação ambiental, que indica:

Quando há mais de um EIA para a mesma bacia hidrográfica, a Feema deverá realizar a análise conjunta dos empreendimentos, para definir a capacidade de suporte do ecossistema, a diluição dos poluentes e os riscos civis, sem prejuízo das análises individuais dos empreendimentos (Rio de Janeiro, 1998) ${ }^{12}$.

Ainda sobre a questão locacional do empreendimento, chamou a atenção de técnicos do IBAMA e do Instituto Chico Mendes (Ibama-ICMBio, 2008) a disparidade entre as três alternativas locacionais apresentadas no EIA (Campos, Itaguaí e Itaboraí) quanto à proximidade do possível local de implantação do empreendimento em relação a unidades de conservação federais e estaduais vizinhas, como dito anteriormente. Em Campos haveria apenas uma unidade de conservação dentro de um raio de $20 \mathrm{~km}$ do local previsto para o empreendimento; em Itaguaí, seria uma UC dentro do raio de $10 \mathrm{~km}$ e mais quatro dentro do raio de $20 \mathrm{~km}$. Na localidade Itaboraí são 2 UCs no raio de $10 \mathrm{~km}$ e mais 6 no raio de $20 \mathrm{~km}$. Ou seja, apesar de a localidade Itaboraí apresentar a maior concentração de unidades de conservação no entorno do local pretendido para o empreendimento - o que indica tratar-se de área com grande interesse para a conservação da biodiversidade -, tal localidade foi apresentada pelo Estudo de Impacto Ambiental como a mais adequada para instalação do Comperj.

Apesar dos impactos ambientais negativos do empreendimento, a grande maioria da população local, de baixa renda e com altos índices de subemprego e desemprego, o apoia. Para isso, opera o fenômeno da

\footnotetext{
${ }^{12}$ Sobre este ponto, vale citar a interpretação dada pelo Ministério Público federal, na Ação Civil Pública 1.30.003.000055/2006-07: “O licenciamento de parte (principal) do Complexo Petroquímico, anterior e isoladamente, além de ocultar a lesividade do conjunto, e obstar a intervenção e análise do órgão protetor das unidades de conservação federais em todo o processo, terá, inevitavelmente o efeito nefasto de induzir a concessão de licença para as demais obras [...] uma vez implantadas as principais instalações do Comperj, e não sendo estas suficientes à operação do empreendimento concebido pela Petrobras, tornar-se-á absolutamente necessária a aprovação das obras complementares. Estará o órgão licenciador, assim, refém das circunstâncias então criadas".
} 
chantagem ambiental ${ }^{13}$, com promessas de melhoria econômica, genericamente, e oferta de empregos, especificamente. A implantação do Comperj é apresentada como a única alternativa para alavancar o desenvolvimento econômico local e seus impactos negativos são olvidados em quaisquer comunicações de massa da Petrobras. Bullard (2004) aponta que elementos de chantagem econômica são comuns na implantação de grandes empreendimentos em áreas ocupadas por populações em condições de subalternidade:

Comunidades economicamente empobrecidas não possuem muitas escolhas. Alguns trabalhadores se tornam desesperados, preferindo empregos perigosos e com baixos salários do que o desemprego. [...] Essa prática se aproxima da chantagem econômica. (Bullard, 2004; grifos nossos).

Adiante, Bullard desenvolve sua tese, reforçando que tal chantagem econômica associa-se fundamentalmente a uma "chantagem do emprego":

Os trabalhadores são frequentemente forçados a fazerem sacrifícios pessoais em termos de proteção e segurança do trabalho. O local de trabalho, nesse caso, é uma arena onde inevitáveis barganhas entre emprego e locais de trabalho perigosos são realizadas e os trabalhadores que procuram manter seus empregos devem trabalhar sob condições que podem ser perigosas para eles, suas famílias e suas comunidades. Esta prática equivale a uma chantagem do emprego e é equivalente a uma escravidão econômica. [...] O conflito, o medo e a ansiedade são usualmente construídos sob a falsa pressuposição de que as regulamentações ambientais estão diretamente relacionadas à perda de postos de trabalho. Embora o fechamento das plantas industriais possa ser apenas uma ameaça, a chantagem é real (Bullard, 2004; grifos no original).

Consoante tal análise, Acselrad \& Bezerra (2010) afirmam a ocorrência da chantagem locacional dos investimentos: a ameaça de deslocalização dos empreendimentos com a colocação dos trabalhadores em situação de competição, não só no que diz respeito ao nível de seus salários, mas também aos direitos e condições normativas destinados a assegurar proteção social e ambiental ${ }^{14}$.

Atraídos pela perspectiva de recursos de royalties, os municípios da região se associaram em um consórcio - Conleste, fomentado pela Petrobras para garantir seu apoio político ao projeto. Em relação ao órgão licenciador estadual (INEA, atualmente; Feema, no início do processo de licenciamento), a Federação das Indústrias do Rio de Janeiro - Firjan - contratou a maior parte do corpo técnico responsável pelo licenciamento prévio do empreendimento, o que gerou implicações éticas sobre a necessária independência entre empreendedor e licenciador. De fato, o alinhamento entre o órgão ambiental e o empreendedor é notável, chegando ao ponto de a Petrobras ter preparado os projetos exigidos pela Feema para a obtenção da licença de instalação antes da própria emissão oficial da licença prévia ${ }^{15}$, o que sugere uma comunicação permanente entre tais entidades ao longo de todas as fases do licenciamento ${ }^{16}$.

O conjunto de elementos que sugerem a inadequação do Comperj na área do Mosaico Central Fluminense

\footnotetext{
${ }^{13}$ Propomos aqui a categoria de "chantagem ambiental" - fenômeno observado em casos de implantação de empreendimentos ambientalmente impactantes em áreas socialmente vulneráveis - associando os conceitos de "chantagem econômica" e "chantagem de emprego" (Bullard, 2004); "chantagem locacional" (Acselrad \& Bezerra, 2010) e "alternativas infernais" (Stengers \& Pignarre, 2005).

${ }^{14}$ Acselrad \& Bezerra (2010) amparam sua análise acerca da chantagem locacional no conceito de alternativas infernais, desenvolvido por Stengers \& Pignarre (2005). Segundo estes autores, o capitalismo mostra-se hoje como um sistema que paralisa e captura os atores sociais no interior de alternativas infernais - situações que parecem não deixar outra escolha além da resignação ou da denúncia impotente ante a guerra econômica incontornável.

${ }^{15}$ Ação Civil Pública 1.30.003.000055/2006-07.

${ }^{16}$ Tal aproximação direta entre a indústria e os órgãos ambientais vem se intensificando no Brasil e merece uma análise pormenorizada, além da dimensão do presente trabalho. Exemplos dessa tendência são a "adoção" de UCs como o parque nacional dos Lençóis Maranhenses, pela MMX, e do parque estadual da Ilha Grande, pela Vale. Não coincidentemente, estas empresas possuem vários empreendimentos poluidores em licenciamento nos mesmos órgãos que gerenciam tais UCs. Não seria incoerente supor que a adoção das UCs possa ser usada como chantagem pelas empresas, em eventuais restrições impostas pelos órgãos ambientais aos empreendimentos solicitados.
} 
levou os conselhos gestores da APA Guapimirim e do próprio mosaico a se manifestarem explicitamente contrários ao empreendimento ${ }^{17}$.

Primeiramente, o conselho gestor da APA Guapimirim apreciou o caso, considerando o impacto direto do empreendimento sobre esta área protegida. Este conselho já vinha se destacando por seu caráter popular, como fórum receptivo à participação direta da população local, por meio do aumento proporcional da representação de associações de moradores, entidades representativas da pesca artesanal e cooperativas locais (Coelho, 2011). Após discutir o caso, o conselho da APA emitiu moção aos órgãos licenciadores denunciando os impactos negativos do empreendimento sobre a área protegida e suas populações locais.

Houve durante as discussões deste caso no conselho da APA Guapimirim um evento emblemático, que ilustra bem as tensões havidas entre os interesses empresariais que acompanham o Comperj e a preocupação com a manutenção do equilíbrio ecológico regional. Uma organização não governamental (Instituto Terra Azul) patrocinada pela Petrobras veio oferecer à UC, por intermédio através de seu conselho gestor, um projeto que apresentava como objetivo a conservação ambiental das águas que banham a APA Guapimirim. O projeto foi apresentado por um representante da ONG e posteriormente debatido pelos conselheiros. Apesar da carência de recursos orçamentários para a gestão da área protegida - fato sobejamente conhecido no conselho -, que poderia ser minorada com o significativo aporte financeiro que o projeto propunha à gestão da UC (algo em torno de um milhão de reais, quantia equivalente a quase uma década de investimentos totais recebidos pela unidade através do repasse ordinário do governo federal), os conselheiros optaram por rejeitar a proposta. Como o conselho tinha ciência de que o processo de licenciamento do Comperj estava em andamento, interpretou-se que a aceitação de um projeto financiado pela Petrobras acarretaria em uma vinculação estreita e direta entre o empreendedor e a UC, que poderia vir a comprometer posicionamentos futuros da administração da APA que viessem a contrariar os interesses da empresa. A gestão da APA estaria "refém" do financiamento oferecido pelo empreendedor, reduzindo, desta forma, sua autonomia técnica ${ }^{18}$. Constata-se aqui outra faceta da chantagem ambiental, neste caso não voltada genericamente às populações locais com ofertas de emprego ou promessas de melhoria de vida, mas sim dirigidas especificamente a instâncias de gestão com atribuições que envolvem temas de interesse corporativo.

Ao longo do processo de licenciamento, o conselho do mosaico também se envolveu diretamente com o Comperj. Representantes da Petrobras foram ao conselho em algumas oportunidades para apresentar o empreendimento e esclarecer os questionamentos dos conselheiros. Da mesma forma, conselheiros que representavam as instituições de pesquisa do Mosaico submeteram à apreciação do colegiado pareceres e posicionamentos sobre os impactos do empreendimento.

Um caso em particular no envolvimento do conselho do Mosaico com este empreendimento merece destaque no âmbito deste artigo: o licenciamento da hidrovia do rio Guaxindiba, empreendimento associado ao Comperj, ocorrido em 2012. Este rio, inserido na APA Guapimirim e no entorno imediato da ESEC Guanabara, foi resguardado administrativamente da possibilidade de

\footnotetext{
${ }^{17}$ Tal posição foi desconsiderada com a emissão da licença prévia pelo órgão ambiental estadual. Ainda assim, após a emissão da licença e embasado pelo posicionamento e pelos argumentos dos Conselhos, posicionou-se o Ministério Público Federal - MPF, através da Ação Civil Pública 1.30.003.000055/2006-07. Nesta ação, o MPF requereu uma liminar suspendendo o licenciamento, o que não foi atendido pelo poder judiciário. ${ }^{18}$ Shanee (2013), ao analisar a reação de populações campesinas peruanas às quais foram oferecidos recursos oriundos de projetos de conservação de grandes ONGs internacionais, constatou três diferentes percepções destas populações acerca deste tipo de oferta de investimento: a) como uma oportunidade para ganhos pessoais; b) como uma oportunidade para sustentar projetos ambientais, que não conseguiriam captar outras fontes de financiamento; e c) quando a conservação ambiental faz parte de alguma luta social, os incentivos financeiros são percebidos como desnecessários, indesejáveis ou até mesmo como obstáculos. O caso relatado do comportamento do conselho da APA Guapimirim enquadra-se na terceira categoria constatada por Shanee. Sem dúvida, trata-se de comportamento muito mais raro, em comparação às duas primeiras categorias, o que aumenta o interesse científico para compreender as motivações das populações em reagir desta forma e sugere considerável maturidade política destas mesmas populações, na medida em que abdicam de investimentos imediatos em favor de manter a consistência e a coerência dos embates socioambientais nos quais estejam envolvidas.
} 
qualquer uso industrial associado ao Comperj, por meio através de posicionamento do IBAMA, assimilado pelo órgão licenciador estadual quando da emissão da licença prévia (LP) do empreendimento. Entretanto, em menos de cinco anos após a emissão da LP, argumentando dificuldades financeiras e logísticas, a Petrobras requereu aos órgãos ambientais a utilização do referido corpo hídrico como hidrovia para o transporte de equipamentos pesados a serem empregados no Comperj. $\mathrm{O}$ assunto foi extensamente debatido pelo conselho do Mosaico, que concluiu pela inviabilidade ambiental da proposta, pois sacrificaria a já combalida pesca artesanal na baía de Guanabara, com a contaminação do pescado por metais pesados, que seriam disponibilizados à biota por conta das dragagens necessárias ao afundamento do leito do rio para permitir a passagem das embarcações industriais.

Tal posicionamento foi firmado em uma moção do conselho ${ }^{19}$, encaminhada aos órgãos licenciadores e a algumas outras entidades, como o Ministério Público, o Congresso Nacional e o Ministério do Meio Ambiente - MMA. Instada pela moção, a Câmara dos Deputados requereu ao MMA explicações sobre o assunto ${ }^{20}$. A mesma moção havia sido encaminhada simultaneamente ao MMA, mas não houve nenhuma resposta deste órgão ao conselho do Mosaico - a ausência de respostas oficiais do MMA ao Mosaico era até então fato comum: nenhum documento encaminhado anteriormente pelo conselho do Mosaico ao MMA havia sido respondido, desde seu reconhecimento oficial. Neste caso, entretanto, após a cobrança da Câmara dos Deputados ao MMA, o Ministério manifestou-se quanto à moção do Mosaico. A resposta do $\mathrm{MMA}^{21}$, contudo, não trouxe nenhuma informação sobre o empreendimento citado, nem sobre os impactos ambientais apontados. Ao contrário, o ofício ministerial resumiu-se a repreender o conselho do Mosaico pelo encaminhamento direto do tema à Câmara dos Deputados, usando para tanto um expediente oficial. O mérito do assunto foi desconsiderado pelo ministério, que se ateve a uma crítica da forma empregada pelo conselho para se manifestar. Ou seja, apesar de o próprio MMA ter sido a instância que oficialmente reconheceu e instituiu o Mosaico Central Fluminense (MMA, 2006), quando provocado a manifestar-se sobre tema de significativa repercussão político-econômica, o MMA optou por não discutir o mérito da questão e, além disso, questionar a própria legitimidade do Mosaico como colegiado oficialmente instituído. Tal comportamento dúbio - ora reconhecendo o Mosaico, quando nenhum embate político de maior envergadura era visível; ora desqualificando o conselho do Mosaico, em outro momento, agora durante uma disputa de interesses entre o capital industrial e a conservação da sociobiodiversidade - indica limites da ação estatal no apoio a causas socioambientais.

Após o caso da hidrovia no rio Guaxindiba ganhar repercussão na mídia nacional e internacional ${ }^{22}$, resultante de grande mobilização institucional e popular ${ }^{23}$, foi arquivado o projeto da Petrobras em utilizar o referido rio (Dias et al., 2013; Faustino \& Furtado, 2013). Certamente o grau de articulação atingido pelas UCs componentes do Mosaico Central Fluminense, associado à mobilização popular encabeçada por conselheiros da APA Guapimirim e do Mosaico, foram decisivos para demover a Petrobras e o governo estadual da utilização do rio Guaxindiba.

\footnotetext{
${ }^{19}$ Carta 3/2012 Mosaico Central Fluminense.

${ }^{20}$ Ofício ATS CMADS n 18/2012, de 10 de setembro de 2012.

${ }^{21}$ Ofício 874/2012/GM/MM, de 30 de novembro de 2012.

${ }^{22}$ Houve matérias sobre o caso em emissoras televisivas da Jordânia - com cobertura para grande parte dos países árabes - (Al Jazeera) e francesa (Arte TV).

${ }^{23}$ No âmbito institucional, além de moções dos conselhos da APA Guapimirim, ESEC Guanabara (conselheiros e demais integrantes da câmara técnica de pesquisa), PARNA Serra dos Órgãos e Mosaico Central Fluminense, houve manifestações oficiais encaminhadas ao MMA pelo Instituto de Biologia-UFRJ, Conselho Nacional da Reserva da Biosfera da Mata Atlântica, Fórum de Atingidos pela Indústria do Petróleo e Petroquímica nas Cercanias da Baía de Guanabara - FAPP/BG, Justiça Global Brasil, dentre outros. Quanto às mobilizações populares, destacaram-se uma ocupação realizada em frente à Assembleia Legislativa do Rio de Janeiro, organizada por pesquisadores e ativistas, com apoio do Sindicato dos Trabalhadores da Petrobras - Sindipetro, em 05 de abril de 2012; e uma barqueata na Baía de Guanabara, organizada por entidades representativas da pesca artesanal, em 15 de novembro de 2012 (data de aniversário da APA Guapimirim).
} 


\section{Considerações finais}

Nesta pesquisa, constatou-se que o referencial associado à ecologia política fornece importantes subsídios para que casos ou conflitos particulares envolvendo questões socioambientais possam ser compreendidos em seus aspectos estruturantes. No caso estudado, a articulação de conceitos da ecologia política com os fatos relatados segue este princípio: a progressiva industrialização do entorno da baía de Guanabara e o consequente afastamento das populações locais de modos de vida diretamente vinculados ao ambiente natural são contextualizados no âmbito da falha metabólica entre sociedade e natureza; a escolha do local de implantação do Comperj, ocupado principalmente por populações de baixa renda, remete ao conceito de zona de sacrifício; as investidas corporativas quanto ao anúncio da oferta de empregos e à disponibilidade de patrocínio para projetos locais aludem à chantagem ambiental; e as contradições analisadas no processo de licenciamento do empreendimento estudado - marcadas pela dissonância entre interesses corporativos privados e questões socioambientais públicas - inscrevem-se no campo de análise do ecologismo dos pobres e da justiça ambiental.

Outrossim, diante dos acontecimentos descritos e da argumentação teórica feita, é possível dizer que o agravamento da crise econômica no Brasil em 2015 pode tornar mais difícil a conciliação da construção e do funcionamento do Comperj com a conservação

\section{Referências}

Acselrad, H. (Org.). Conflitos ambientais no Brasil. Rio de Janeiro: Relume Dumará, 2004.

Acselrad, H.; Bezerra, G. Desregulação, deslocalização e conflito ambiental: considerações sobre o controle das demandas sociais. In: Almeida, A. W. B. (Org.). Capitalismo globalizado e recursos territoriais: fronteiras da acumulação no Brasil contemporâneo. Rio de Janeiro: Ford Foundation, Lamparina, 2010. p. 179-210.

Acselrad, H.; Mello, C. C. A.; Bezerra, G. N. O que é justiça ambiental. Rio de Janeiro: Garamond, 2009. ambiental da região. Diante da perspectiva de recrudescimento das pressões político-econômicas associadas ao Comperj sobre as unidades de conservação e o conjunto de atores sociais que dela dependem e defendem, é importante o reconhecimento de que "os conflitos em que seja intenso o desequilíbrio de poder entre os que colhem as vantagens econômicas da produção e os que pagam os custos ambientais são precisamente aqueles onde a vitória é menos provável" (Gould, 2004). Para fazer frente a tamanho desafio tornam-se imperiosos avanços na luta e na organização das populações atingidas, associadas às unidades de conservação e a entidades de apoio (universidades, entidades de direitos humanos) sem os quais dificilmente se ultrapassará o patamar das pequenas concessões (Vainer, 2001). A organização da resistência ambiental deve assumir estratégias políticas transescalares (Vainer, 2001), ou seja, além de reforçar os movimentos de resistência local, devem ser construídas estratégias de ampliação da escala de atuação.

No caso em tela, a articulação das UCs no Mosaico Central Fluminense segue este princípio, dado que uma posição assumida pelo conjunto de unidades de conservação, associada à ampliação da participação social das populações diretamente envolvidas, tem necessariamente mais magnitude e importância do que posicionamentos particulares e isolados. Constatamos aqui um efetivo papel dos mosaicos na qualificação e no aprofundamento da participação social na gestão de áreas protegidas.

Alencar, E.; Galdo, R. Pouco gás nas obras do Comperj. $O$ Globo, Rio de Janeiro, 06 de abril de 2015.

Almeida, A. W. B. (Org.). Capitalismo globalizado e recursos territoriais: fronteiras da acumulação no Brasil contemporâneo. Rio de Janeiro: Ford Foundation, Lamparina, 2010.

Amador, E. S. Baía de Guanabara e ecossistemas periféricos. Rio de Janeiro: Edição do autor, 2000.

Beck, U. Sociedade de risco: rumo a uma outra modernidade. Rio de Janeiro: Saraiva, 2010. 
Brandão, C. Acumulação primitiva permanente e desenvolvimento capitalista no Brasil contemporâneo. In: Almeida, A. W. B. (Org.) Capitalismo globalizado e recursos territoriais: fronteiras da acumulação no Brasil contemporâneo. Rio de Janeiro: Ford Foundation, Lamparina, 2010. p. 39-70.

Brasil. Lei n. 9.985, de 18 de julho de 2000. Institui o Sistema Nacional de Unidades de Conservação. Brasília: DOU de 19/07/2000.

Bullard, R. Dumping in Dixie: race, class and environmental quality. San Francisco/Oxford: Westview Press, 1994.

Bullard, R. Enfrentando o racismo ambiental no século XXI. In: Acselrad, H.; Pádua, J. A. (Orgs.). Justiça ambiental e cidadania. Rio de Janeiro: Relume Dumará, 2004. p. 41-68.

Coelho, B. H. Valoração de manguezais impactados por petróleo: o caso da Reduc-RJ. Rio de Janeiro, Dissertação (Mestrado em Planejamento Ambiental) - UFRJ, 2002.

Coelho, B. H. Participação das populações locais no conselho gestor da APA Guapimirim: empecilhos e avanços In: Medeiros, R.; Araújo, F. (Orgs.). Dez anos do Sistema Nacional de Unidades de Conservação da Natureza: lições do passado, realizações presentes e perspectivas para o futuro. Brasília: MMA, 2011. p. 89-102.

CONAMA - Conselho Nacional do Meio Ambiente. Resolução 01, de 23 de janeiro de 1986. Brasília: DOU de 17/02/86.

Concremat. Estudo de impacto ambiental do Comperj. Rio de Janeiro: Petrobras, 2007.

Costa, C.; Lamas, I.; Fernandes, R. Planejamento estratégico do Mosaico Central Fluminense. Teresópolis, 2010. Mimeo.

Delelis, C.; Rehder, T.; Cardoso, T. Mosaicos de áreas protegidas: reflexões e propostas da cooperação franco-brasileira. Brasília: Ministério do Meio Ambiente. 2010.

Dias, A.; Souza, A.; Maia, A.; Berzins, A. Complexo Petroquímico do Rio de Janeiro (Comperj): impactos socioambientais, violação de direitos e conflitos na baía de Guanabara. Revista Ética e Filosofia Política, 1(16), 151-175, 2013.

Faustino, C.; Furtado, F. Indústria do petróleo e conflitos ambientais na Baía de Guanabara. Rio de Janeiro: DHESCA, 2013.

Feema-Serla. Plano diretor de recursos hídricos da região hidrográfica da Baía de Guanabara. Rio de Janeiro: Consórcio Ecologus/Agrar, 2005.

Foster, J. B. A ecologia de Marx: materialismo e natureza. Rio de Janeiro: Civilização Brasileira, 2005.
Freire, L. Seguindo Bruno Latour: notas para uma antropologia simétrica. Comum, Rio de Janeiro, 11(26), 46-65, 2006.

Giddens, A. As consequências da modernidade. São Paulo: UNESP, 1990.

Giuliani, G. M. A questão ecológica, a indústria e o capitalismo. Raizes, 19, 9-15, 1999.

Gould, K. A. Classe social, justiça ambiental e conflito político. In: Acselrad, H.; Pádua, J. A. (Orgs.). Justiça ambiental e cidadania. Rio de Janeiro: Relume Dumará, 2004. p. 69-80.

Ibama-ICMBio. Manifestação técnica sobre os impactos ambientais potenciais decorrentes da implantação do Comperj nas unidades de conservação federais da região. Rio de Janeiro, 2008. Mimeo.

ICMBio. Mosaicos reconhecidos oficialmente. Disponível em: <http://http://www.icmbio.gov.br/portal/o-que-fazemos/ mosaicos-e-corredores-ecologicos/moscaicos-reconhecidos-oficialmente.html>. Acesso em 19 mai. 2014.

Irving, M. Áreas protegidas e inclusão social: uma equação possível em políticas públicas de proteção da natureza no Brasil? Sinais Sociais, 12(4), 122-147, 2010.

Langenbach, T.; Amador, E.; Coelho, B. H. Conquista da comunidade científica. Ciência Hoje, 43, 59-61, 2008.

Latour, B. Reassembling the social. An introduction to actornetwork theory. Oxford: University Press, 2005.

Law, J. Notes on the theory of the actor network: ordering, strategy and heterogeneity. Systems Practice, 5, 379-393, 1992. Disponível em: <http://heterogeneities.net/publications/ Law1992NotesOnTheTheoryOfTheActorNetwork.pdf>.

Leher, R. Iniciativa para a integração da infraestrutura regional da América Latina, Plano de Aceleração do Crescimento e a questão ambiental: desafios epistêmicos. In: Loureiro, C. F. (Org.). A questão ambiental no pensamento crítico: natureza, trabalho e educação. Rio de Janeiro: Quartet, 2007. p. 223-255.

Leroy. J. P.; Meireles, J. Povos indígenas e comunidades tradicionais: os visados territórios dos invisíveis. In: Porto, M. F.; Pacheco, T.; Leroy, J. P. (Orgs.). Injustiça ambiental e saúde no Brasil. Rio de Janeiro: Fiocruz, 2013. p. 115-132.

Loureiro, C. F. B. Sustentabilidade e educação: um olhar da ecologia política. São Paulo: Cortez, 2012.

Loureiro, C. F. B.; Layrargues, P. P. Ecologia política, justiça e educação ambiental crítica: perspectivas de aliança contra-hegemônica. Trabalho, Educação e Saúde, 11(1), 53-71, 2013. 
Loureiro, C. F. B.; Rezende, D.; Corrêa, F.; Praça, M.; Vargens, M.; Franca, N. Aprendizados e reflexões: em que a experiência do projeto contribui para pensar os desafios da gestão de mosaicos no Brasil. In: Loureiro, C. F.; Franca, N. (Orgs.). Mosaicos da Mata Atlântica: caminhos a partir da experiência de um projeto. Rio de Janeiro: IBASE, 2014. p. 54-60.

Lukács, G. Ontologia do ser social. São Paulo: Boitempo, 2013.

Martínez Alier, J. O ecologismo dos pobres: conflitos ambientais e linguagens de valoração. São Paulo: Contexto, 2011.

Melo, G. Desafios para a gestão integrada e participativa do Mosaico da Mata Atlântica Central Fluminense. Tese (Doutorado em Psicossociologia de Comunidades e Ecologia Social) - EICOS/UFRJ, 2012.

MMA - Ministério do Meio Ambiente. Portaria 350, de 11 de dezembro de 2006. Disponível em: <http://www.icmbio.gov. $\mathrm{br} /$ portal/images/stories/mosaicos/portaria-central-fluminense. pdf $>$. Acesso em: jun. 2015.

Pacheco, T.; Faustino, C. A iniludível e desumana prevalência do racismo ambiental nos conflitos do Mapa. In: Porto, M. F.; Pacheco, T.; Leroy, J. P. (Orgs.). Injustiça ambiental e saúde no Brasil. Rio de Janeiro: FIOCRUZ, 2013. p. 73-114.

Paula, J. A. Crise econômica e reiteração do capitalismo dependente no Brasil. In: Almeida, A.; Zhouri, A.; Ioris, A.;
Brandão, C.; Berman, C.; Hernandéz, F.; Bezerra, G.; Acselrad, H.; Paula, J.; Laschefski, K.; Coelho, M.; Monteiro, M.; Garzon, L.; Cunha, L.; Wanderley, L. Capitalismo globalizado e recursos territoriais. Rio de Janeiro: Lamparina, 2010. p. 9-38.

Rio de Janeiro. Lei 3.111, de 18 de novembro de 1998. Disponível em: $<$ http://alerjln1.alerj.rj.gov.br/CONTLEI.NSF/c8aa0 900025feef6032564ec0060dfff/46feb5cb70bd1433032566c10 075dba9? OpenDocument>. Acesso em: maio 2015.

Shanee, N. Campesino justification for self-iniciated conservation actions: a challenge to mainstream conservations. Journal of Political Ecology, 20, 413-428, 2013.

Soares, D. G. Conflito, ação coletiva e luta por direitos na baía de Guanabara. Rio de Janeiro, Tese (Doutorado em Sociologia) - UFRJ, 2012.

Stengers, I.; Pignarre, P. La sorcellerie capitaliste. Paris: La Décourvete, 2005.

Vainer, C. B. As escalas de poder e o poder das escalas: o que pode o poder local? In: Anais do Encontro da ANPPUR, 2001. p. 140-151.

Visvanathan, S. A Carnival for Science. Essays on Science, Technology and Development. Delhi: Oxford University Press, 1997.

Zhouri, A.; Valencio, N. (Orgs.). Formas de matar, de morrer e de resistir: limites da resolução negociada de conflitos. Belo Horizonte: Editora da UFMG, 2014. 